\title{
Using a parachute course to retain students in introductory physics courses
}

\author{
Rebecca Lindell ${ }^{1,2}$, Patrick Coulombe ${ }^{3}$, and Jeff Saul ${ }^{2}$ \\ ${ }^{1}$ Purdue University, Department of Physics and Astronomy \\ 525 Northwestern Avenue, West Lafayette, IN 47907 \\ ${ }^{2}$ Tiliadal STEM Education \\ 12200 Academy Road NE, Albuquerque, NM 87111 \\ ${ }^{3}$ University of New Mexico, Educational Psychology Program \\ MSC05-3040, Albuquerque, NM 87131-0001
}

\begin{abstract}
Calculus-based introductory physics service courses tend to be on the top twenty most difficult or killer course lists at many colleges and universities. At University of New Mexico (UNM), with a large minority-enrollment, physics faculty developed a parachute course to address this high failure rate and to improve student retention. Students not doing well in Physics 1 can switch into this course mid-semester when it begins and the original course is dropped from their records. The course has two goals: help students maintain their GPA to keep their scholarships and help them learn skills and knowledge needed to be successful on their next attempt at Physics I. Although the course was successful in helping students maintain their GPA; it seemed to do little to reduce the overall failure rate. Students retaking Physics I after the parachute course did no better than students retaking Physics I who did not take it.
\end{abstract}

\section{INTRODUCTION}

College students tend to view introductory physics courses as some of the most difficult on campus. It is not surprising for these courses to often have comparatively high drop, failure, and withdrawal (DFW) rates, i.e. the fraction of students who fail to pass the course with at least a $\mathrm{C}$ in the course. At many schools, calculus-based and algebra-based introductory physics courses are both in the top twenty killer courses list [1].

In 2012, President Obama made a national call for an increase of STEM majors by over a million in the next ten years. The majority of these STEM majors will need to successfully pass introductory physics courses. If we want to increase the number of STEM graduates, then we need to increase student retention and passing rates for students in the introductory physics sequences. We need to stop thinking of these courses as killer courses and start thinking about them as courses designed to help a larger fraction of students learn the material and pass. Or to paraphrase Redish and Steen, we need to make these courses more of a pump than a filter. [2]

Many physics departments have attempted to reduce DFW rates in their introductory physics courses using one of the following ways.

- Making the course more student-centered by changing the format of the course. For example, Studio format courses such as Studio Physics [3], SCALE-UP [4], ISLE [5], and Modeling Instruction [6] have reported reductions in DFW rates of 40 to $60 \%$ for introductory physics courses compared to the lecture/laboratory versions of the same course.

- Having at-risk students participate in mandatory outof-class instruction, e.g. tutoring and/or supplemental instruction.

- $\quad$ Requiring pre-physics/math course(s) to help identified at-risk students better prepare for introductory physics courses.

Another possible solution to improve student retention and improve DFW rates is to institute a parachute course. A parachute course is similar to the pre-physics/math course mentioned above, except that the parachute course starts mid-term and runs to the end of the semester so students who are not doing well in introductory physics course can switch into it without penalty or additional cost. The purpose of this special course is twofold, to help these students

1. maintain their GPA (and help retain scholarships) and

2. develop the knowledge and skills related to force and motion needed to succeed in the physics I course in the future.

In this paper we will examine the parachute course offered at the University of New Mexico from 2009-2015 and how well it achieves the two goals described above.

\section{BACKGROUND}

The University of New Mexico is located in Albuquerque, New Mexico. Albuquerque has about 1/3 the population of the state of New Mexico and is over 5 times larger than the next largest city. Culture shock is a major 
issue for students coming from outside the Albuquerque area. The state has the largest percentage Hispanic population of any US state. However, New Mexico has two different Hispanic cultures, the descendants of the original Spanish settlers who came here 400 years ago and the more recent Hispanic immigrants. New Mexico also has the $2^{\text {nd }}$ highest percentage Native American population. New Mexico is typically in the bottom 5 states of per capita wealth, economic, and education measures. These are reflected in the population of the university.

The University of New Mexico is a metropolitan university with less than $10 \%$ of students living on campus. It has an academic rating of 64 in the Princeton Reviews. UNM annually enrolls 20,000 students with an average age of 24 , with a large fraction of first generation college students, Student population is $40 \%$ Hispanic and $5 \%$ Native American. Many students are on scholarship most provided by the state lottery scholarship program. The sixyear graduation rate is $47 \%$ and the freshman retention rate is $77 \%$ [7]

The UNM Department of Physics \& Astronomy offers a three semester calculus-based physics sequence primarily for engineering majors and a two semester algebra-based sequence primarily for life science majors. Both courses are three credits and meet for three hours per week. In addition, there is an associated optional one-credit one-hour per week discussion section and a separate optional onecredit three-hour per-week laboratory course. Some major programs require students to take the laboratory course while others do not so not all students take the associated laboratory.

DFW rates for the algebra-based physics 1 course are much smaller (18-20\%) and typically only a few students at most each term switch into the parachute course. For this reason, from here on "Physics I" will refer to calculusbased Physics I.

For the Physics I course, course size is 80-300 students with 1-2 sections per semester, usually a larger morning MWF course and a smaller evening MW course. Typically, 30-50 students in the morning section and 15-30 students in the evening section sign up for discussion sections, which are run by the course instructor. All calculus-based Physics I instructors use the department recommended text, Young and Freedman, University Physics [8].

Students who do not perform well in Physics I may choose to switch into the parachute course. The students start over in terms of their grade and the physics I course is removed from their transcript. In effect, the parachute course replaces the Physics I course in the students' record and gives them a fresh start.

Excluding students who switch into the parachute class, the DFW rates from the Physics I course still range from $40-70 \%$ depending on the instructor teaching the course [9]. Almost all the students who switch into the parachute course come from this Physics I course. The larger the
DFW rates, the more students switch into the parachute course.

\section{THE PARACHUTE COURSE}

Originally developed in 2006, the University of New Mexico implemented a physics parachute course for the reasons stated above. The program has run continuously during the fall and spring semesters since then [10].

The course begins the Monday after mid-semester break and meets four-days (MTWTh) per week for the remainder of the semester from 7:30-8:45 AM so as not to interfere with students' existing courses. Students who are not passing Physics I before mid-semester are encouraged by their instructors to switch into the parachute class. Students who wish to switch to the parachute course from Physics I must sign a form requesting the switch at midsemester. The registrar processes these forms manually and the faculty arrange for switching the students web-based homework system accounts (this also allows switching students electronic access to a textbook more suitable for the parachute course that emphasizes conceptual understanding and multiple representations, Knight, Physics for Scientists and Engineers [11]. Note that there is no additional cost to the student to switch from physics I to the parachute course. The original Physics I course is removed from the student's record and replaced with the parachute course. Prior to Spring 2014, a small number of students (10-15) would typically register for the parachute course as a physics preparatory course.

The instructional staff of the parachute course includes one instructor, an in-course Teaching Assistant, and an outof-course grader. It must be noted that the student to instructor ratio is smaller and the in-course contact hours are greater than the Physics I course. From the onset, the parachute course utilized an activity-based format with small student groups to build knowledge and skills in the context of force and motion including problem solving, vectors, and algebra.

One of the authors taught the course from fall 2009 to Spring 2015 with exception of Spring 2012. He continued the activity-based format, but instituted structured groups of 3-4 students each. The curriculum focused on the first five units of the Modeling Instruction Mechanics curriculum (available from the American Modeling Teachers Association) [12]. In addition, extra materials on vector analysis, cooperative group problem solving, and an emphasis on doing symbolic algebra supplemented the modeling curriculum. For most activities, students summarize their solutions for in-course activities on whiteboards and then have a question and answer session to discuss the results. Laboratory activities are incorporated as needed as in-course activities.

Since students who switched were unable to cope with the pace or level of difficulty of the Physics I course, the parachute course is taught at a slower pace with less 
homework than the Physics I course. Also the grading standards allow for passing with a $\mathrm{C}$ based on effort, but students are informed that they need to get a B or better in the parachute course to be prepared to be successful in Physics I in a later term.

\section{RESULTS AND DISCUSSION}

As stated earlier, the parachute course has two objectives:

1. To help students who are not successful in Introductory Physics I courses maintain their GPA and improve their retention at the university and in their major programs. This includes helping them keep the scholarships that help students in their programs.

2. To help those students develop key skills and knowledge to help them be more successful when retaking Physics 1 in the future.

The success of the course is measured by how well we met these two objectives. The results have been mixed so far.

As can be seen in Table 1, we were quite successful with the first objective. Only $21 \%$ of the students in the parachute course failed to get at least a C. Thus out of a student population unable to pass Physics I, roughly four out of 5 passed the slower, activity-based parachute course. This helped them maintain their GPAs and thus their scholarships that enable them to stay at UNM. And $45 \%$ of students passed at a level compatible with passing Physics I.

TABLE 1. UNM Physics parachute course results over 11 semesters.

\begin{tabular}{|l|c|c|c|}
\hline \multicolumn{1}{|c|}{ Term } & $\begin{array}{c}\text { Course } \\
\text { Size }\end{array}$ & DFWs & B or Better \\
\hline Fall 2009 & 21 & 3 & 12 \\
\hline Spring 2010 & 25 & 2 & 13 \\
\hline Fall 2010 & 25 & 7 & 12 \\
\hline Spring 2011 & 31 & 9 & 11 \\
\hline Fall 2011 & 40 & 3 & 19 \\
\hline Fall 2012 [13] & 54 & 8 & 12 \\
\hline Spring 2013 & 26 & 8 & 8 \\
\hline Fall 2013 & 43 & 6 & 32 \\
\hline Spring 2014 & 16 & 4 & 7 \\
\hline Fall 2014 & 29 & 10 & 13 \\
\hline Spring 2015* & 75 & 22 & 34 \\
\hline \multicolumn{1}{|c|}{ Totals } & $\mathbf{3 8 5}$ & $\mathbf{2 1 \%}$ & $\mathbf{4 5 \%}$ \\
\hline
\end{tabular}

* Large student numbers required teaching parachute course as an evening section in physics lecture hall.

Additionally, Table 1 shows a drop in the parachute physics course enrollment starting in Spring 2014. This was due to a full semester 3 hours per week math/physics prep course being offered that year to better prepare students to take Physics I. Only a few students per term took the parachute course as physics prep course after this full-semester prep course started.

In Spring 2015, the day course for calculus-based Physics I was unusually large (course size exceeded the 280 student capacity of the classroom for the first time). This resulted in an unusually large number of students switching into the parachute course. The classroom was changed to the physics large lecture hall with fixed seats that could accommodate the large course size and have easy access to physics demonstrations but was not conducive to group activities. Laboratory experiments had to be conduced as demonstrations and student groups had to be asked to sit near the aisle so that instructors could easily interact with them and monitor their progress. More experience and thought is needed to optimize the curriculum for a large lecture hall.

The results for the $2^{\text {nd }}$ objective are less clear. The hope was that students who took the parachute course and then retook Physics I would be more successful than students retaking Physics I without the parachute course. To study this issue, we conducted a longitudinal study of the parachute course from Fall 2009 through Fall 2014.

We conducted all of our analyses in the statistical programming environment $\mathrm{R}$. When introducing covariates in the final analysis, we estimated the regression model using the structural equation modeling package lavaan [14] with full-information maximum likelihood estimation. The steps we utilized are shown below.

- Converted letter grades to numeric values with dropped, failed with an $\mathrm{F}$, or $\mathrm{W}=0, \mathrm{D}_{-}=1, \ldots, \mathrm{A}+=$ 12.

- Ran several linear regression analyses correlating the numerical grade in Physics I with whether or not the students

1. enrolled in the parachute course,

2. enrolled in the parachute course and passed with a grade of B or better,

3. passed the parachute course with a grade of B or better compared with student who did not take the parachute class.

As a follow-up we also looked at other predictive factors such as undergraduate GPA, Physics I instructor, high school GPA, and ACT mathematics and composite scores to examine the effectiveness of the parachute course for students who were otherwise equivalent on these covariates.

Results of our analysis are as follows:

- Students who did not take the parachute course $(\mathrm{N}=180)$ had a slightly lower mean grade (between $\mathrm{C}$ and $\mathrm{C}+$ ) when they retook Physics I than those who did take the parachute course $(\mathrm{N}=105)$ this difference was not statistically significant $[\mathrm{B}=0.30(\mathrm{SE}=0.39)$, 


$$
\mathrm{t}(283)=0.76, \mathrm{p}=.447]
$$

- Students who passed the parachute course with a grade lower than B (B-, C+, C-) before retaking Physics I had a mean grade of $\mathrm{C}$ - in Physics I while those who passed with a B or better had a mean grade between $\mathrm{C}+$ and $\mathrm{B}-$ . This difference is statistically significant $[\mathrm{B}=2.74$ $(\mathrm{SE}=.65), \mathrm{t}(102)=4.19, \mathrm{p}<.001]$.

- Students who passed the parachute course with a B or better had a mean grade (between $\mathrm{C}+$ and $\mathrm{B}-$ ) when they retook Physics I compared with a retake grade average between $\mathrm{C}$ and $\mathrm{C}+$ for those students who did not take the parachute course. The difference is statistically significant $[\mathrm{B}=1.14(\mathrm{SE}=0.44), \mathrm{t}(250)=$ $2.60, \mathrm{p}=.010]$.

However, when students' UNM cumulative GPA and other covariates were taken into account in the regression analysis, there was no significant difference in average grade when retaking Physics I between the students who received a $\mathrm{B}$ or better in parachute course and those students who retook Physics I without taking the parachute course $[\mathrm{B}=-0.13(\mathrm{SE}=0.35)$, Wald $\mathrm{z}=-0.36, \mathrm{p}=.716]$. Conversely, students with higher UNM GPAs in general also tended to obtain higher grades in Physics 1 in particular $[\mathrm{B}=4.00(\mathrm{SE}=0.32)$, Wald $\mathrm{z}=12.58, \mathrm{p}<.001]$.

This suggests that the better students (students with higher UNM cumulative GPAs) who are failing to pass Physics 1 at midterm are taking the parachute course.

\section{CONCLUSIONS}

In this paper we found that the UNM parachute course does a help students avoid a failing grade, but does not necessarily improve their grades when they retake Physics I compared to students who retook Physics I without taking the parachute course.

Suggestions for improving the parachute course

[1] In this paper, students dropping courses during the Add/Drop period in the first 3 weeks of the semester are not counted in the DFW rate.

[2] E.F. Redish, J. Appl. Dev. Psych (2000) and I.A. Steen, DC Math. Assoc. of America (1988).

[3] K. Cumming, J. Marx, R. Thornton, and D. Kuhl, Am. J. Phys. 67 S38 (1999).

[4] R.J. Beichner et al., in Research-based Reform of University Physics, edited by E.F. Redish and P. Cooney (AAPT, College Park MD, 2007).

[5] S.W, Brahmin, In PERC Invited Paper series, v, 1064 (2008), p. 7.

[6] E. Brewe et al, PRST-PER 6010106 (2010)

[7] Six-year graduation rate from Princeton Review online and Freshman Retention rate from US News \& World Report online (both retrieved 7/11/2016).

8] H. Young and R. Freedman, University Physics (Pearson, San Francisco CA, 2015). include:

- $\quad$ Starting the course earlier in the term and allow time to more fully cover force and motion.

- Heavily recruiting more failing Physics 1 students into the parachute course to have larger impact on student success.

- Study specific issues that parachute students have when retaking Physics I to help guide improvements.

- Reexamine the curriculum to see how it can be improved.

- Consider letting the parachute course be a lead-in for an alternate studio-style sequence of introductory physics for high-risk students that would count the same as the current calculus-based sequence. Including the semester with the parachute course, it would take three semesters studio-style to complete the requirement of the first two traditional semesters of introductory physics. Brahmia [5] found that after two semester of an alternate introductory physics sequence taught studio style, students were able to succeed in upper division courses at a comparable rate to students who completed a traditional two-semester lecture/lab sequence for introductory physics.

- Interviewing former students of both Physics 1 and the Parachute course to generate a needs assessment and doing a demographic analysis are logical next steps.

\section{ACKNOWLEDGEMENTS}

The authors would like to thank Kathy Dimiduk for originally developing the parachute course at UNM and Richard Rand for our discussions on how to measure success in the parachute course. In addition, we would like to thank the UNM STEM Gateways program and UNM Office of institutional effectiveness for their assistance.

[9] Students who switch from Physics I into the parachute course are removed from the roster of the Physics I course and are not included in the DFW rate determined once final grades have been submitted.

[10] K. Dimiduk left UNM in summer 2008 to become Director of the James McCormick Family Teaching Excellence Institute in the College of Engineering at Cornell University. Saul was hired to succeed her.

[11] R. Knight, Physics for Scientists and Engineers, (Pearson, San Francisco CA, 2016).

[12] Modeling Instruction curriculum materials are available from the American Modeling Teachers Association website with membership at https://modelinginstruction.org.

[13] Due to scheduling issues the Spring 2012 parachute course was taught by a senior graduate student who had been a teaching assistant for Saul twice before. No data was available from this course.

[14] Y. Rosseel, J. Stat. Softw., 48, 1-36 (2012). 